Vol 13, Issue 6, 2020

\title{
A COMPARATIVE STUDY OF ANTI-NOCICEPTIVE ACTIVITY OF CURCUMA LONGA LINN. WITH THAT OF IBUPROFEN IN EXPERIMENTAL ANIMALS
}

\author{
SWOPNA PHUKAN, SAHELI DAS* \\ Department of Pharmacology, Gauhati Medical College, Guwahati, Assam. Email: sahelidas037@gmail.com
}

Received: 21 February 2020, Revised and Accepted: 24 March 2020

\begin{abstract}
Objective: The aim of the study is to evaluate and compare the analgesic activities of Curcuma longa Linn. in the experimental animals.

Methods: The present study was conducted in the Department of Pharmacology, Gauhati Medical College and Hospital, after getting approval from the Institutional Animal Ethics Committee (No MC/68F/2009/MAR-19/02). Healthy rodents weighing between 150 and 200 g were selected and randomly divided into five groups, each group consisting of six animals. Tail-flick analgesiometer was used to assess the analgesic activity of $C$. longa Linn. and ibuprofen in the experimental animals. Appropriate statistical analyses like Student's t-test were used to analyze the data.
\end{abstract}

Results: The mean reaction time (s) was prolonged on gradually increasing the dose of C. longa Linn. from 200 to $400 \mathrm{mg} / \mathrm{kg}$. At $400 \mathrm{mg} / \mathrm{kg}$ dose C. longa Linn. produced similar analgesic activity as compared to ibuprofen $(30 \mathrm{mg} / \mathrm{kg})$.

Conclusion: From the study, it can be concluded that curcumin has the capacity to attenuate pain, and when administered in high doses, may produce similar activity as other conventional NSAID's.

Keywords: Curcuma longa, Ibuprofen, Anti-nociceptive activity.

(C) 2020 The Authors. Published by Innovare Academic Sciences Pvt Ltd. This is an open access article under the CC BY license (http://creativecommons. org/licenses/by/4. 0/) DOI: http://dx.doi.org/10.22159/ajpcr.2020.v13i6.37224

\section{INTRODUCTION}

Curcumin is the active ingredient of turmeric. It belongs to the family Zingiberacea. Curcumin has been extensively used in Ayurveda and traditional Indian System of Medicine since a very long time. It has been observed that curcumin has a lot of benefits on a person's health, as discussed by Sodhi et al. [1]. It can act as an anti-inflammatory, as shown by Arora et al. [2], antibacterial, antipyretic, antioxidant, and analgesic agent.

Studies done by Chandra et al. [3] and Deodhar et al. [4] showed that curcumin was effective in arthritis. It is also used in the treatment of fever, Alzheimer's disease, skin conditions like acne, eczema, inflammatory bowel disease, heart diseases.

Other studies done by Bose et al. [5] and Mehta et al. [6] also highlighted the beneficial activity of curcumin in the treatment of different types of cancer.

A few studies like that done by Jagetia et al. [7] have shown that turmeric when taken in the diet on a regular basis has helped to boost the immune system of an individual.

Due to the excellent health benefits of turmeric, a lot of turmeric supplements have flooded the market.

Ibuprofen is a type of NSAID. They work by inhibiting the production of inflammatory mediators like prostaglandin which is responsible for causing pain, inflammation, and fever. Cooper et al. [8] studied the analgesic activity of ibuprofen. Ibuprofen and other NSAID's are associated with a lot of side effects, including gastric ulcer and interstitial nephritis on prolonged use.

The purpose of the study is to evaluate whether curcumin present in turmeric has got significant analgesic activity and can be used as an alternative to the conventional NSAID's in the treatment of painful conditions.

\section{METHODS}

The study was conducted in the Department of Pharmacology, Gauhati Medical College and Hospital after obtaining approval from the Institutional Animal Ethics Committee (No MC/68F/2009/ MAR-19/02).

Thirty healthy Wistar rats weighing between 150 and $200 \mathrm{~g}$ of either gender were selected and allocated in five groups. Each group comprised of six animals.

They were maintained on a pellet diet and water was givenad libitum. The animals were acclimatized for 1 week before the experiment. The duration of the study was 21 days.

Chemicals and drugs

1. Syrup ibuprofen $(100 \mathrm{mg} / 5 \mathrm{ml})$

2. Crude curcumin extract was purchased from HIMEDIA Laboratories Pvt. Limited (RM1449-10G).

\section{Grouping of animals}

Group 1 - (Control group): N/S $0.5 \mathrm{ml}$

Group 2 - (Standard drug): Syp ibuprofen $30 \mathrm{mg} / \mathrm{kg}$

Group 3 - Test group - Curcuma longa crude extract $100 \mathrm{mg} / \mathrm{kg}$ body weight

Group 4 - Test group - C. longa crude extract $200 \mathrm{mg} / \mathrm{kg}$ body weight Group 5 - Test group - C. longa crude extract $400 \mathrm{mg} / \mathrm{kg}$ body weight

The animals in Group 1 and Groups 3, 4, and 5 were administered drugs once daily for 21 consecutive days until the final day of the experiment.

\section{Methods: Tail-flick analgesiometer}

The reaction time (in seconds) was noted down, which was the time from the onset of placing the tail on the heated wire and flicking of the tail from the source of heat. The tail was not kept for more than $15 \mathrm{~s}$ to prevent thermal damage to the tail. 
Table 1: The mean reaction time (in seconds) at the beginning of the experiment and again at the end of $60 \mathrm{~min}$

\begin{tabular}{|c|c|c|c|}
\hline Groups & Drug & $\begin{array}{l}\text { Mean reaction time }(\mathrm{s}) \pm S E M \text { at beginning } \\
\text { of experiment at } 0 \mathrm{~min}\}\end{array}$ & $\begin{array}{l}\text { Mean reaction time }(\mathrm{s}) \pm S E M \\
\text { at the end of } 60 \mathrm{~min}\}\end{array}$ \\
\hline Group 1 & $\mathrm{~N} / \mathrm{S}$ & $7.03 \pm 0.04$ & $7.2 \pm 0.04$ \\
\hline Group 2 & Ibuprofen $30 \mathrm{mg} / \mathrm{kg}$ & $7.1 \pm 0.05$ & $11.4 \pm 0.18$ \\
\hline Group 3 & Curcuma longa $100 \mathrm{mg} / \mathrm{kg}$ & $7.25 \pm 0.10$ & $8.3 \pm 0.13$ \\
\hline Group 4 & Curcuma longa $200 \mathrm{mg} / \mathrm{kg}$ & $7.3 \pm 0.17$ & $9.2 \pm 0.12$ \\
\hline Group 5 & Curcuma longa $400 \mathrm{mg} / \mathrm{kg}$ & $7.3 \pm 0.05$ & $10.4 \pm 0.15$ \\
\hline
\end{tabular}

*SEM: Standard error of mean. p value was highly significant (p<0.0001) among Groups 1 and 2, Groups 1 and 4, Groups 1 and 5, Groups 2 and 3, Groups 2 and 4, Groups 3 and 5

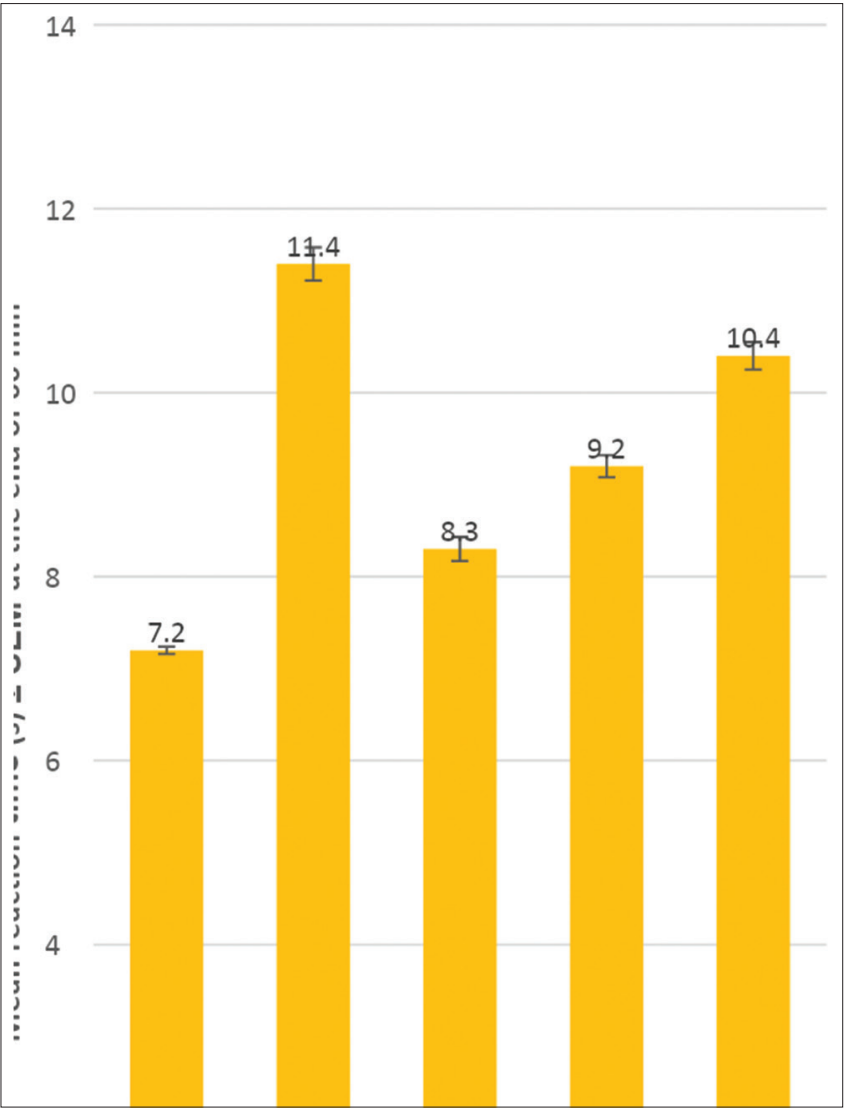

Fig. 1: Comparison of the anti-nociceptive activity of different groups (at the end of $60 \mathrm{~min}$ )

\section{Data analyses}

Descriptive statistics and inferential statistics such as Students t-test and GraphPad were used to evaluate the data findings. $\mathrm{P}=0.05$ was fixed as the level of significance.

\section{RESULTS}

In the present study, the mean reaction time (s) was noted down before the beginning of the experiment (at $0 \mathrm{~min}$ ) and again at the end of 60 min after administering the drugs (Table 1 and Fig. 1).

\section{DISCUSSION}

The $C$. longa Linn. crude extract was given in increasing doses of 100 , 200, and $400 \mathrm{mg} / \mathrm{kg}$ doses, respectively, to Groups 3, 4, and 5 for 21 days.

Groups 1 and 2 were administered N/S and ibuprofen.

By the tail-flick analgesiometer method, the mean reaction time in seconds was noted down before the administration of the drugs and once again after the administration of the drugs at the end of $60 \mathrm{~min}$.
The study revealed that the mean reaction time at the end of 60 min was increased in Groups 2, 3, 4, and 5.

Group 2 (ibuprofen $30 \mathrm{mg} / \mathrm{kg}$ ) showed the highest increase in mean reaction time $(11.4 \pm 0.18 \mathrm{~s})$. It was also observed that with the gradual increase in the dosage of curcumin, the mean reaction time also increased gradually.

Group 5 (curcumin $400 \mathrm{mg} / \mathrm{kg}$ ) produced nearly similar analgesic activity (mean reaction time $-10.4 \pm 0.15 \mathrm{~s}$ ) as compared to Group 2 (ibuprofen $30 \mathrm{mg} / \mathrm{kg}$ ) whose mean reaction time was $11.4 \pm 0.18 \mathrm{~s}$ at the end of $60 \mathrm{~min}$.

Studies done by Neha et al. [9] and Sharma et al. [10] showed similar results. Furthermore, C. longa (400 mg/kg) and ibuprofen $(30 \mathrm{mg} / \mathrm{kg}$ ) almost have comparable anti-nociceptive activity.

Other studies conducted by Ojewole et al. [11] and Hajare et al. [12] also revealed the analgesic activity of some other plant compounds such as Zingiber officinale and Dalbergia sissoo leaves similar to the analgesic activity exhibited by curcumin present in turmeric.

Other than analgesic activity, curcumin also possesses anti-inflammatory activity which has been demonstrated by Sulthana et al. [13] on osteoarthritis patients.

Curcumin along with azadirachta indica was also shown to exhibit antifungal activity by Saini et al. [14].

\section{CONCLUSION}

From the study, we can conclude that curcumin has got significant analgesic activity with a gradual increase in its dose.

The anti-nociceptive activity of curcumin can be utilized to treat a lot of chronic pain conditions such as arthritis, cancer, diabetes, and multiple sclerosis and thereby minimize the use of NSAID's which can have a negative impact on the health on prolonged use.

One major drawback of curcumin is that it has verypoor oral bioavailability when given through oral route which can be effectively countered by giving curcumin with piperine or nanocurcumin formulations.

\section{ACKNOWLEDGMENT}

The author is thankful to the Professor and HOD, Department of Pharmacology, for providing laboratory facilities to conduct the study.

\section{AUTHORS' CONTRIBUTION}

All the authors contributed to the preparation of the final manuscript.

\section{CONFLICTS OF INTEREST}

None declared.

\section{FINANCIAL SUPPORT AND SPONSORSHIP}

Nil. 


\section{REFERENCES}

1. Sodhi V. Ayurvedic Science Update: Turmeric for Cancer; 2006. Available from: http://www.ayurvedicscience.com. [Last accessed on 2019 Dec 10].

2. Arora RB, Kapoor V, Basu N, Jain AP. Anti-inflammatory studies on Curcuma longa (Turmeric). Indian J Med Res 1971;59:1289-95.

3. Chandra D, Gupta S. Anti-inflammatory and anti-arthritic activity of volatile oil of Curcuma longa (Haldi). Indian J Med Res 1972;60:138-42.

4. Deodhar SD, Senthi R, Srimal RC. Preliminary study on antirheumatic activity of curcumin (diferuloyl methane). Indian $\mathrm{J}$ Med Res 1980;71:632-4

5. Bose S, Panda AK, Mukherjee S. Curcumin and tumor immune-editing: Resurrecting the immune system. Cell Div 2015;10:6.

6. Mehta K, Pantazis P, Mc Queen T, Aggarwall BB. Antiproliferative effect of curcumin (diferuloylmethane) against human breast tumor cell lines. Anticancer Drugs 1997;8:470-81.

7. Jagetia GC, Aggarwal BB. Spicing up of the immune system by curcumin. J Clin Immunol 2007;27:19-35.

8. Cooper SA. The relative efficacy of ibuprofen in dental pain. Compend Contin Educ Dent 1986; 7:578, 580-1, 584-8

9. Neha S, Ravir GD, Jangade CR. Analgesic and antipyretic activities of Curcuma longa rhizome extracts in Wister rats. Vet World 2009;2:304-6.

10. Sharma A, Rauniar GP. Antinociceptive effects of purified Curcuma longa in mice. Int J Basic Clin Pharmacol 2016;5:484-90.

11. Ojewole JA. Analgesic, antiinflammatory and hypoglycaemic effects of ethanol extract of Zingiber officinale (Roscoe) rhizomes (Zingiberaceae) in mice and rats. Phytother Res 2006;20:764-72.

12. Hajare SW, Chandrika S, Tandan SK, Sarma J, Lal J, Telang AG. Analgesic and antipyretic activities of Dalbergia sissoo leaves. Indian J Pharmacol 2000;32:357-60.

13. Sulthana N, Vijaya K, Madhavi BB. Effect of curcumin on chemically induced osteoarthritis. Int J Pharm Pharm Sci 2017;9:182-7.

14. Saini A, Saini G, Singh B, Vyas M, Verma S, Prakash O. Synergistic effect of Azadirachta indica and Curcuma longa with fluconazole gel against Candida albicans. Int J Pharm Pharm Sci 2018;10:692-700. 